\title{
DiáRIO do Ano InTERnacional da Química
}

Diário publicado neste número do Boletim da Sociedade Portuguesa de Química compila o conjunto de actividades realizadas no âmbito do Ano Internacional da Química e do Centenário da SPQ durante os meses de Agosto, Setembro e Outubro de 2011.

\section{Agosto}

ExPosiçõEs E OUtros Eventos:

Exposição "Química em Flash" No âmbito das comemorações do Ano Internacional da Química, a Fábrica Centro Ciência Viva de Aveiro e o Departamento de Química da Universidade de Aveiro promoveram "Química em flash", um concurso de fotografia científica. Este desafio teve como objectivo motivar e sensibilizar o público escolar e geral para a Química que existe à nossa volta, incentivando a criatividade e imaginação aliadas a esta área científica. Os melhores trabalhos do concurso "Química em Flash" estiveram em exposição na Reitoria da Universidade durante o mês de Agosto.

Livros e PublicaçõEs:

Newsletters mensal SPQ e quinzenal AIQ

\section{Setembro}

LivRos e PublicaçõEs:

Boletim SPQ - Química 122

Exposições e Outros Eventos:

A Química na Festa do Avante - A convite da organização, a SPQ participou, de forma estritamente científica, na Festa do Avante (Seixal, 2-4 de Setembro), cujo pavilhão de ciência foi este ano dedicado à Química. Na zona de demonstrações interactivas estiveram presentes o Departamento de Química da Faculdade de Ciências e Tecnologia da UNL (João Carlos Lima, João Sotomayor, entre outros), com experiências dedicadas à Fotoquímica, Polímeros e Gastronomia Molecular, para além de outros temas. Foram ainda proferidas as palestras "A História Química de uma Vela de Michael Faraday" (Sérgio Rodrigues e Filipa Oliveira, FCT-UC) e "Viva a
Química" (ITQB-UNL, Carlos Romão). Houve ainda uma sessão sobre o Ano Internacional da Química e o Centenário da SPQ, com a presença do Prof. Rui Namorado Rosa (UE) e do Presidente da SPQ (Mário Nuno Berberan e Santos). Para além das iniciativas em que a SPQ colaborou, incluindo (como consultora) uma excelente exposição em painéis ilustrados sobre a Química nos seus variados aspectos, que poderá ser requisitada por escolas interessadas, falou-se da "Química no Universo" (Máximo Ferreira e Ana Maria Dias) e o Núcleo de Estudantes de Física do IST também apresentou várias demonstrações relacionadas com Química. A iniciativa foi sempre muito participada, tendo passado pelo pavilhão vários milhares de pessoas.

\section{CONGRESSOS:}

III Jornadas Ibéricas de Fotoquímica Data: 4 a 7 de Setembro

Local: Universidade de Granada, Espanha

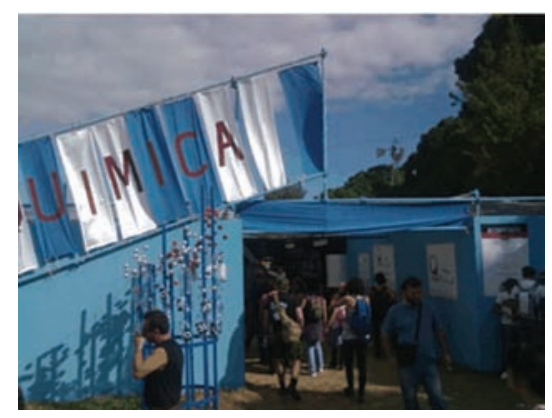

1

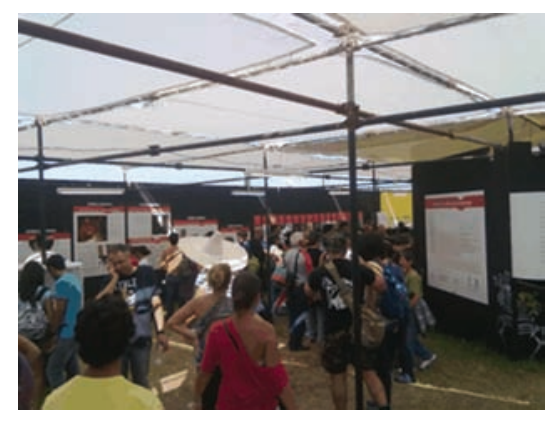

3 5th Iberian Carbohydrate Meeting GLUPOR 9

Data: 4 a 7 de Setembro

Local: Universidade de Trás-os-Montes e Alto Douro, Vila Real

AcÇÕES DE FORMAÇÃo / WORKSHOPS: Actividades Laboratoriais para 0 $12^{\circ}$ Ano

Data: 5 a 10 de Setembro

Local: Departamento de Química e Bioquímica da Faculdade de Ciências da Universidade do Porto

Tópicos de Química Física para Compreensão do Mundo Actual

Data: 7 de Setembro a 6 de Outubro Local: Departamento de Química e Bioquímica da Faculdade de Ciências da Universidade do Porto

\section{CONGRESSOS:}

Glycosciences in the International Year of Chemistry: Applications to Human Health and Disease

Data: 8 a 10 Setembro

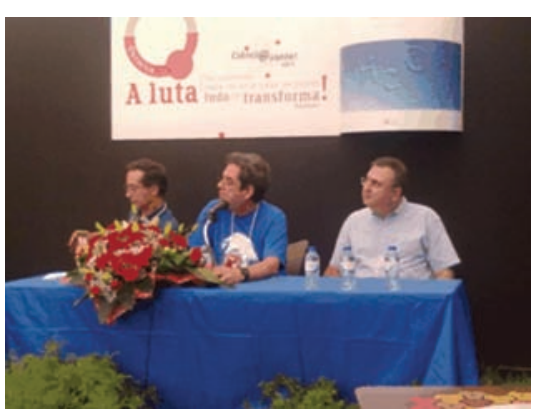

2

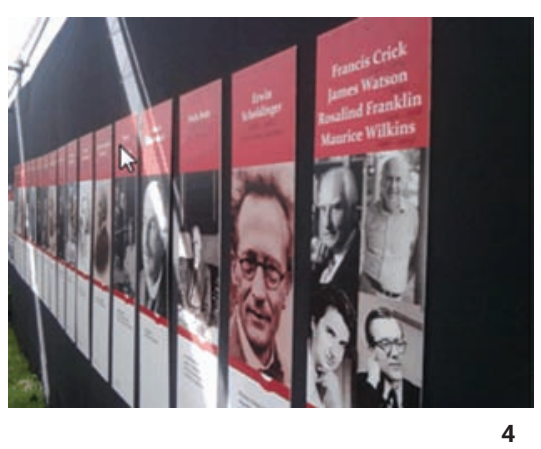

1, 3 e 4 - Pavilhão da química na Festa do Avante; 2 - Sessão sobre o AIQ 2011 e o Centenário da SPQ 
Local: Faculdade de Ciências da Universidade de Lisboa

\section{Encontro da rede SUPRAPHONE - SUPRAMOLECULAR PHOTONICS NETWORK IN EUROPE}

O Centro de Química da Madeira da Universidade da Madeira organizou, de 7 a 10 de Setembro, a conferência anual da rede europeia SUPRAPHONE - Supramolecular Photonics Network in Europe. A conferência teve lugar no Hotel CS Madeira e contou com a participação de vários oradores convidados, entre os quais os Professores Xiangyang Shi, titular da Cátedra Santander em Nanotecnologias na Universidade da Madeira, Carsten Schmuck, da Universidade de DuisburgEssen, na Alemanha, e Makoto Fujita, da Universidade de Tóquio, no Japão.

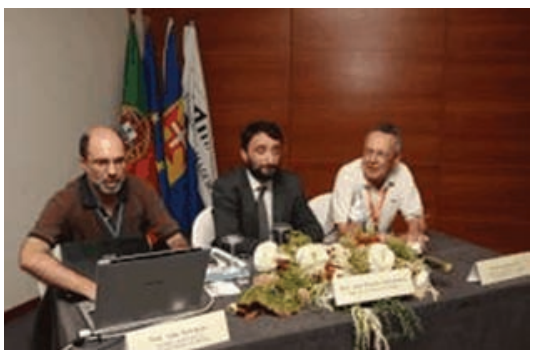

Encontro da Rede SUPRAPHONE

EXPOSIÇÕES E OUTROS EVENTOS:

Exposição VIDA E OBRA DE MARIA SKLODOWSKA-CURIE (1867-1934) De 9 de Setembro a 9 de Outubro, o Centro Comercial Dolce Vita Douro, em Vila Real, recebeu a exposição sobre a vida e obra desta investigadora, a primeira mulher a conquistar um Prémio Nobel. A exposição foi organizada em colaboração com os Arquivos da Academia das Ciências da Polónia e o Museu de Maria Skłodowska Curie, em Varsóvia. A versão portuguesa foi da autoria da Comissão para o AIQ do Departamento de Química da Universidade do Minho. De 10 de Outubro a 8 de Novembro esta exposição esteve também disponível no Átrio da Química da Reitoria da Universidade do Porto.

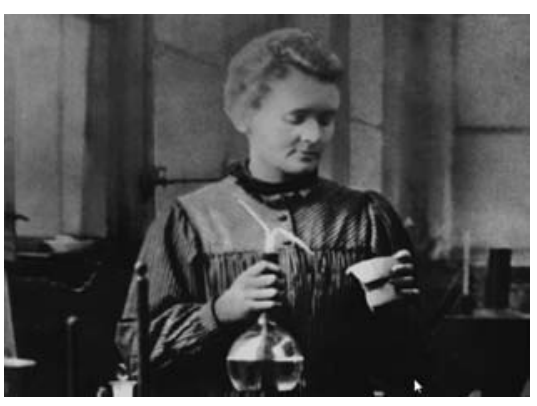

Maria Skłodowska Curie
CONFEREnCias / Palestras: GOLDEN CHEMISTRY

O ciclo de conferências GOLDEN CHEMISTRY levou, à Universidade da Madeira, uma série de personalidades ligadas à Química.

"Networking molecular cages and capsules" - Prof. Makoto Fujita, Universidade de Tóquio, Japão - 12 de Setembro

"Multicomponent transition metal complexes: from charge separation to light-driven molecular machines" - Prof. Jean-Pierre Sauvage, Northwestern University, EUA - 13 de Outubro

Produtos Audiovisuais:

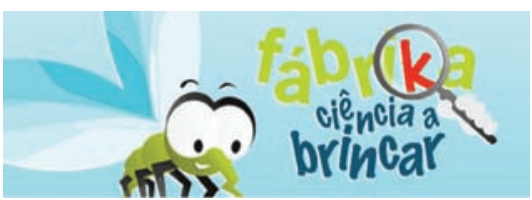

Fábrika: Ciência a Brincar

"Fábrika, Ciência a Brincar" é um magazine de divulgação científica dedicado ao público mais jovem, com emissão na SIC K e produzido pela Fábrica Centro Ciência Viva de Aveiro. Este programa surge como resultado de uma parceria que a Fábrica Centro Ciência Viva de Aveiro e a Universidade de Aveiro iniciaram com a SIC. O projecto contempla já duas séries de episódios e visto estarmos no Ano Internacional da Química, alguns abordaram conceitos de química. A primeira série, de 10 episódios, estreou no dia 13 de Setembro. A segunda série, de 12 episódios, estreou a 11 de Outubro.

\section{ConferênCIAs / PALEstras:}

Light-induced water splitting and hydrogen production in nature - Wolfgang Lubitz, Max Planck Institute of Bioinorganic Chemistry - Mülheim an der Ruhr, Germany 15 de Setembro, Biblioteca da Faculdade de Ciências e Tecnologia da Universidade Nova de Lisboa

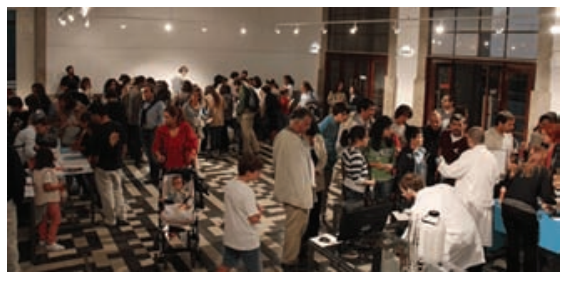

Noite da Química no Porto
CONGRESSOS:

III Simpósio Internacional de AMONET

Data: 17 e 18 de Setembro

Local: Fundação Calouste Gulbenkian

CONFERÊNCIAS / PALESTRAS:

'Mare nostrum': lessons in chemical diversity - Ana Lobo, REQUIMTE- FCT/UNL-Caparica, Portugal 21 de Setembro, Biblioteca da Faculdade de Ciências e Tecnologia da Universidade Nova de Lisboa

\section{EXPOSIÇÕES E OUTROS EVENTOS:}

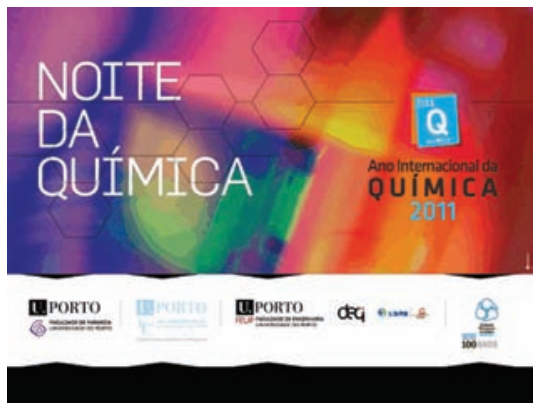

Noite da Química :: Porto e Bragança A Noite da Química, um evento realizado no âmbito do Ano Internacional da Química, ocorreu em simultâneo nas cidades do Porto e de Bragança a partir do final de tarde do dia 23 de Setembro. Esta foi uma noite diferente em que todos, de todas as idades, puderam apreciar ao vivo a beleza da química em todas as suas vertentes. O programa constava de actividades de demonstração e experiências realizadas ao vivo, actuações de tunas, fóruns de discussão, poesia, e muito mais. No Porto, três Faculdades da Universidade do Porto (Faculdade de Engenharia, Faculdade de Ciências e Faculdade de Farmácia) que promovem o ensino da química juntaram-se no Átrio da Química da Reitoria da Universidade do Porto, a partir das 18 h00 para uma noite memorável. Quanto a Bragança, o Centro de Ciência Viva foi o local da festa promovida pelo Instituto Politécnico de Bragança, com início às $21 \mathrm{~h} 00$.

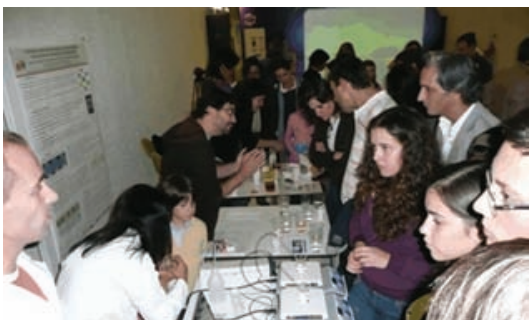

Noite da Química em Bragança 
EXPOSIÇÕES E OUTROS EVENTOS:

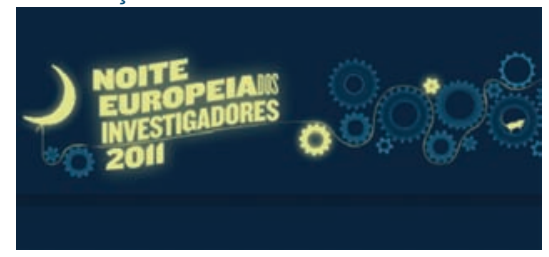

Noite Europeia dos Investigadores (NEI)

A NEI permite a cientistas e ao público em geral conviverem num ambiente descontraído, fomentando a troca de ideias e experiências e dando a conhecer o quotidiano profissional e pessoal dos cientistas e investigadores. A 23 de Setembro, a Noite Europeia dos Investigadores esteve de volta! Portugal participou mais uma vez nesta iniciativa que une toda a Europa. Com esta grande festa da Ciência pretendeu-se suscitar a curiosidade dos jovens pela ciência e pelos vários métodos de investigação e demonstrar que a ciência não é tão complicada como habitualmente se julga. A NEI foi comemorada por todo o país, contando com a participação de várias Instituições e Centros Ciência. Esta iniciativa foi promovida pela Comissão Europeia, o $7^{\circ}$ Programa-Quadro e Marie Curie Actions.

\section{Expressão Plástica e Artística: \\ Teatro "Questão de Ar"}

No âmbito das comemorações do Ano Internacional da Química, foi desenvolvida uma peça de teatro para comunicar ciência com o título "Questão de Ar". Esta peça resultou de uma parceria entre a Fábrica Centro Ciência Viva de Aveiro e os Departamentos de Física e de Comunicação e Arte da Universidade de Aveiro. "Questão de Ar" é dirigida ao público em geral, maiores de 12 anos, e foi novamente apresentada no dia 23 de Setembro na Fábrica Centro de Ciência Viva de Aveiro.

\section{ConferênCIAs / Palestras:}

\section{Ciclo de Cafés de ciência}

Num ambiente não-formal, na companhia de ilustres convidados e saboreando um agradável café, a conversa fluiu por entre os incontáveis pormenores científicos presentes no dia-a-dia, nomeadamente:

\section{- Conversas à vela}

Esta iniciativa resultou da parceria entre a Fábrica Centro Ciência Viva de Aveiro e o Sporting Clube de Aveiro.
O evento decorreu no dia 24 de Setembro, no Hotel Moliceiro, e contou com Delmar Conde como convidado, um velejador e construtor naval de referência.

\section{- Ciência gourmet}

Actividade da Fábrica Centro Ciência Viva de Aveiro resultante de uma parceria com a Latina Adega. Esta sessão abordou, no passado dia 30 de Setembro, os ovos-moles de Aveiro e contou com Manuel A. Coimbra, do Departamento de Química da Universidade de Aveiro e Patrícia Naia, da Apoma, como convidados.

\section{One Century of chemical adventure} in genetics - Wanda Viegas, CBAA/ ISA, Portugal

28 de Setembro, Biblioteca da Faculdade de Ciências e Tecnologia da Universidade Nova de Lisboa

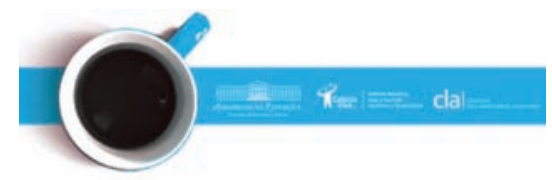

Café de Ciência :: Química para um futuro sustentável

No dia 28 de Setembro, o Café de Ciência na Assembleia da República foi dedicado à Química e aos seus impactos na sociedade. A Química está cada vez mais presente no nosso quotidiano. Alimentação, vestuário, medicamentos, próteses, papel, tintas, construção e energia fazem parte de um universo onde a Química é um factor de inovação. Novas moléculas, que possam servir de base para novos medicamentos e novos materiais, são apenas alguns exemplos do impacto da Química nas nossas condições de vida. Um futuro sustentável depende da nossa capacidade para produzir mais com menos recursos. A Química cria novos processos de produção, com menor impacto ambiental e com menor dispêndio de energia e de matérias-primas. Este Café de Ciência abriu um debate informal entre deputados e especialistas desta área científica, de forma a reforçar redes de contactos para apoiar a decisão política no conhecimento científico. Foi uma iniciativa conjunta da Ciência Viva e da Comissão Parlamentar de Educação, Ciência e Cultura, em parceria com o CLA - Con- selho dos Laboratórios Associados. Este ano o Café de Ciência contou também com a colaboração da Sociedade Portuguesa de Química. Foram abordados os impactos da Química na sociedade, nomeadamente:

×Ambiente: a revolução da Química Verde

× Saúde: do apoio ao diagnóstico à produção de novos fármacos

× Alimentação: da produção e conservação à gastronomia molecular

x Energia: maior eficiência e menor impacto ambiental

x Materiais: das novas próteses às roupas funcionais

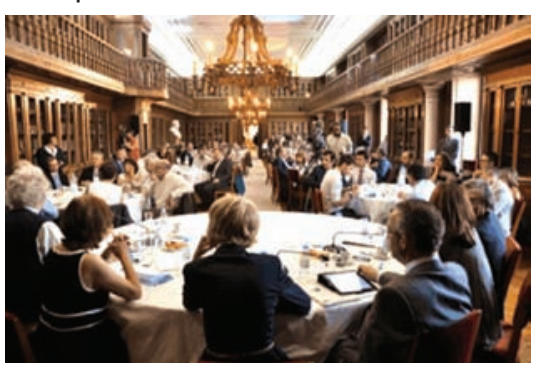

Exposições E Outros Eventos:

Noite da Química :: Covilhã

O Departamento de Química convidou os seus alunos a participarem na Sessão de Boas Vindas que se realizou no dia 29 de Setembro, no âmbito da "Noite da Química", comemorando o Ano Internacional da Química.

\section{Programa:}

21h00 Abertura pelo Magnífico Reitor da UBI

Vice-Reitor para o Ensino e Internacionalização

Presidente da Faculdade de Ciências Presidente do Departamento Química 21h30 Experiências

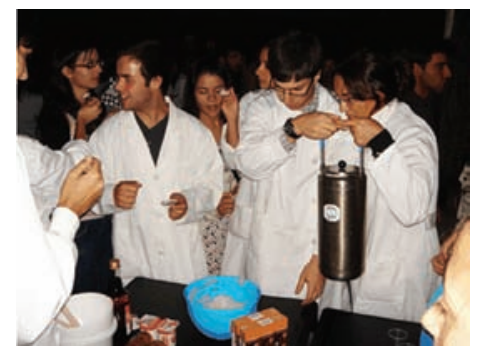

Experiência na Noite da Química da Covilhã

LiVRos E PuBlicAçõES:

Newsletters mensal SPQ e quinzenal AIQ

\section{Outubro}

ConferênCIAs / PALEstras:

Stereoselective reactions promoted by metal-free catalysts, Prof. Maurizio Benaglia, Departamento de Quími- 
ca Orgânica e Industrial, Universidade de Milão

6 Outubro, Colégio Luís António Verney, Évora

"A Química vista por... um artista" - Heitor Alvéolos

7 de Outubro, Anfiteatro Departamento de Química e Bioquímica da Faculdade de Ciências da Universidade do Porto

Congressos:

Nanoschool 2011 - "From chemical topology to cages and molecular machines: the transition metal approach", Professor Convidado: Prof. Jean-Pierre Sauvage, Northwestern University, EUA

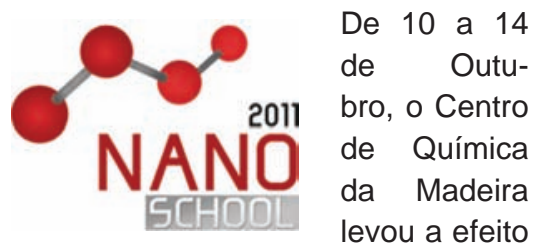

a sua quarta edição da Nanoschool, desta vez tendo, como convidado especial, Jean-Pierre Sauvage, Professor da University of Strasbourg e da Northwestern University (EUA), e membro da Academia Francesa de Ciências. Foi ainda apresentada a palestra, aberta ao público em geral, no dia 12 de Outubro, intitulada "Multicomponent transition metal complexes: from charge separation to light-driven molecular machines".

\section{ExPOSIÇÕES E OUtRos EvEntos:}

Semana da Química em Estarreja As empresas Air Liquide, AQP, Cires, CUF e Dow, em parceria com a Câmara Municipal de Estarreja, promoveram de 11 a 14 de Outubro de 2011 uma semana dedicada à Química. O evento teve lugar no Cine-Teatro de Estarreja e contou com a participação de mais de 3500 alunos. Destinou-se a todos os alunos, do $1^{\circ}$ ciclo ao $12^{\circ}$ ano, das escolas do Concelho de Estarreja. Organizado no âmbito do Ano Internacional da Química (AIQ), contou com duas sessões diárias de um espectáculo didáctico, "Química por Tabela 2.0" (produzido e encenado pela Fábrica - Centro Ciência Viva), totalmente dedicado ao tema da Química, pretendendo sensibilizar os jovens para a descoberta desta ciência, provando que também se pode aprender fora da sala de aula e de forma divertida.
CONFERÊNCIAS / PALESTRAS:

Interactions of DNA with cationic surfactants and proteins: gels and nanoparticles - Maria da Graça Miguel, Universidade de Coimbra, Portugal

12 Outubro, Biblioteca da Faculdade de Ciências e Tecnologia da Universidade Nova de Lisboa

\section{Produtos Audiovisuais:}

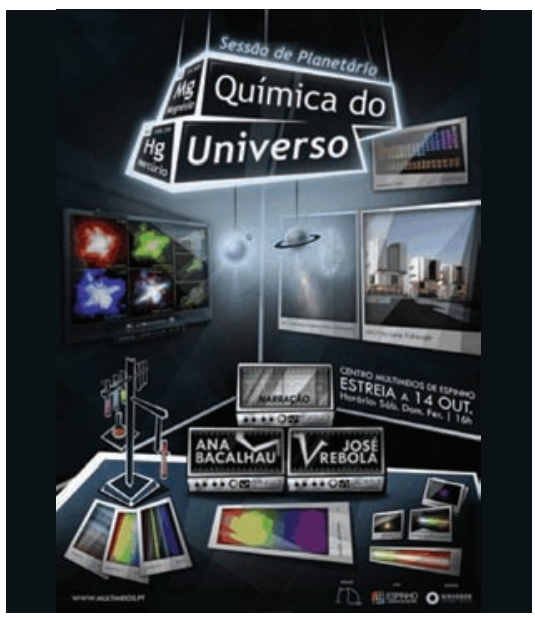

Química do Universo

A Fundação Navegar apresentou a nova sessão de Planetário, "Química do Universo", que estreou no dia 14 de Outubro. Associando-se ao Ano Internacional da Química, o Planetário de Espinho apresentou uma sessão sobre a "Química no Universo", na qual aborda a forma como os diferentes fenómenos e interacções se manifestam no cosmos. Conta com dois apresentadores muito especiais: Ana Bacalhau dá a sua voz a uma Estrela e José Rebola a um Cientista. Juntos desvendam os mistérios do maior de todos os laboratórios: o Universo. A sessão integra-se num conjunto de sessões que o Planetário de Espinho tem disponíveis ao público, adequadas aos diferentes níveis de ensino e a distintas faixas etárias, acompanhando as mais recentes potencialidades tecnológicas e visuais, criando uma sessão com um carácter visual

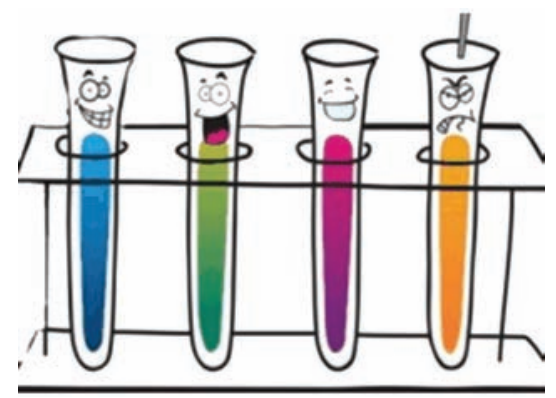

Semana da Química em Estarreja muito forte. Esta sessão é dirigida em particular aos estudantes do $2^{\circ}$ Ciclo e Secundário, procurando integrar duas ciências afins, a Astronomia e a Química, mas poderá ser apreciada por toda a família. Está em exibição desde 15 de Outubro, aos Sábados, Domingos e Feriados, às 16h00.

AcÇÕES DE FORMAÇÃo / WORKSHOPS: Estrutura de Proteínas: da Ciência para a Arte

As proteínas são máquinas moleculares ubíquas no mundo biológico, desempenhando uma enorme variedade de funções que vão desde o suporte estrutural à regulação da expressão genética, passando pela defesa, transporte e catálise de milhares de reacções químicas que ocorrem nos organismos vivos. Estas variadíssimas funções são suportadas por estruturas moleculares tridimensionais complexas que permitem interacções com um elevado grau de especificidade com as moléculas alvo, sejam elas outras proteínas, ácidos nuclei$\cos$ (ADN e ARNs) ou pequenos compostos (metabolitos, medicamentos, xenobióticos). Entender a função das proteínas e actuar na modelação da sua actividade de forma racional implica antes de tudo conhecer a sua estrutura tridimensional. A visualização e análise da estrutura tridimensional de proteínas, no passado uma tarefa reservada a um número muito restrito de especialistas, está hoje em dia acessível a todos. Um computador pessoal e uma ligação à internet é tudo o que é necessário.

Nesta acção, foi apresentada uma ferramenta informática intuitiva e de acesso livre - YASARA View - que pode ser usada na sala de aula para que professores e alunos dissequem as complexidades da estrutura proteica e assim melhor entendam o papel central das proteínas na manutenção da Vida.

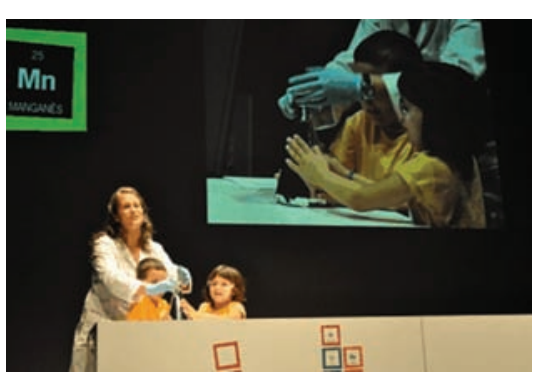

믐ำ 
Como exemplo de aplicação do estudo da estrutura de proteínas, foi feita uma breve introdução às estratégias actuais de procura computacional de compostos com potencial terapêutico e como os cidadãos, através da plataforma de computação voluntária Ibercivis, podem participar nesta procura. Esta sessão contou com o apoio da associação Nova Agora - CFAE - e fez parte das comemorações do Ano Internacional da Química 2011. Realizou-se no dia 15 de Outubro no Museu da Ciência da Universidade de Coimbra.

\section{Produtos Audiovisuais:}

A Química na Rádio Renascença :: Há Química por todo o lado: no amor, na roupa, na cozinha...

Há Química por todo o lado... e este ano ainda mais!

Mesmo que não Ihe demos muita importância ou mesmo que tenha sido a disciplina que menos gostámos quando estávamos na escola, a Química está em quase tudo no nosso dia-a-dia. Do seu perfume preferido, ao seu almoço, passando pelas sensações que invadem o seu cérebro e o seu corpo quando vê aquele alguém especial, a química está sempre lá! E agora a química também está na Renascença! De 17 a 21 de Outubro a Rádio Renascença (RR) convidou os seus ouvintes a saber como a química explica muito do que se passa à nossa volta e como tem um papel relevante para aumentar o nosso bem-estar. Para tal, bastava acompanhar as reportagens e as entrevistas e aproveitar para desfazer algumas ideias préconcebidas sobre a química. Não é porque um produto tem químicos que isso tem de ser necessariamente negativo, já pensou como seria a água que bebemos se não fosse tratada? Pode agradecer... à Química! Deixe o rádio ligado na Renascença para saber a influência da química na cozinha, na roupa ou até no amor!

\section{Outubro:}

Descubra a química no seu dia-adia!

Talvez nem desconfie, mas a Química está presente nos momentos mais simples do seu dia como, por exemplo, quando está a lavar os dentes.

Cristina Oliveira, investigadora da Faculdade de Ciências, ajuda-o a descobrir que, afinal, a Química não ficou lá longe, nos seus tempos de escola.

\section{Esta $2^{\mathrm{a}}$, descubra a química que te-} mos!

A RR vai falar-lhe de um dos grandes "bichos de sete cabeças" do ensino a Química! Esta noite, descubra como ela está presente em tantas coisas do nosso dia-a-dia.

\section{Outubro:}

Já ouviu falar em roupa inteligente e funcional?

Maria José Lourenço é Professora do Departamento de Química e Bioquímica da Faculdade de Ciências da Universidade de Lisboa. Faz investigação na área da Nanotecnologia e um dos seus trabalhos é perceber, por exemplo, como a Química se pode aplicar naquilo que usamos todos os dias como, por exemplo, a roupa. Descubra como a roupa pode ser inteligente e funcional... tudo graças à Química!

\section{Outubro:}

Podíamos viver sem a Química?

Se calhar até podíamos, mas não seria a mesma coisa!

Medicamentos, roupa, as cores que conhece, enfim, a Química está em todo o lado e é por isso que é tão importante prestar atenção ao que vai acontecer a propósito deste Ano Internacional da Química. Para que fique a par de tudo, esta terça-feira, a Sónia Santos e o Joaquim Luís Faria, Secretário-Geral da Sociedade Portuguesa de Química, explicam-Ihe por que é que esta disciplina, que tantas vezes tem uma conotação negativa, faz parte da vida de todos nós!

\section{Sabe qual é a cor da Química?}

A Química é verde.

Quem o diz é Joaquim Luís Faria. Ele é Secretário-Geral da Sociedade Portuguesa de Química e explicaIhe por que é que esta disciplina, que tantas vezes tem uma conotação negativa, também é... verde! Medicamentos, roupa, as cores que conhecemos, enfim, a Química está em todo o lado e, por isso mesmo, 2011 é o Ano Internacional da Química. Em Portugal, a Sociedade Portuguesa de Química é a entidade que está a promover a maioria das iniciativas.

\section{Outubro:}

Aquilo da "química entre duas pessoas" existe mesmo?

A RR fala-lhe da química do amor, nomeadamente, das substâncias que actuam no nosso organismo - no cérebro em particular - e que são responsáveis pelas sensações e comportamentos que associamos ao Amor.

\section{Química: uma ciência apaixonante}

Esta é uma ciência que está presente em vários momentos da sua vida e até, imagine, no amor. Filomena Martins é Professora de Química na Faculdade de Ciências de Lisboa e, dia após dia, leva os seus sentimentos mais humanos até ao laboratório.

\section{Outubro:}

Química: do laboratório para a sua cozinha

$\mathrm{Na}$ sua cozinha acontecem, a todo o instante, reacções químicas: descubra a sua influência na sua alimentação.

É a base da cozinha molecular: analisar, do ponto de vista científico, os fenómenos que ocorrem quando se cozinha. Porquê? Oiça a explicação de Joana Moura, investigadora ligada à área da alimentação.

\section{Não negue à partida uma ciência} que desconhece!

Saiba como a Química pode ajudá-lo a ter uma alimentação mais saudável. $\mathrm{Na}$ sua cozinha acontecem, a todo o instante, reacções químicas. Sabia? Joana Moura é investigadora ligada à área da alimentação e explica-lhe porque é que é bom conhecer melhor alguns dos fenómenos químicos que acontecem na sua cozinha, de modo a conseguir tirar disso o melhor para si!

\section{Onde está a química no seu dia-a- dia?}

Acha que consegue achar a química na sua cozinha?

A RR vai dar-lhe uma ajuda a encontrar a química dentro da sua própria casa. Na sua cozinha também há química, sabia?

\section{Conferências / Palestras:}

Chemistry and the Chemist Public Awareness of their contributions to Society and the Health Care Industry, Bill Heggie, Hovione, Sociedade de Química S. A., Portugal

Dia 19 de Outubro na Biblioteca da 
Faculdade de Ciências e Tecnologia da Universidade Nova de Lisboa

“...Uma Questão de Química” Conferência $A$ Química é quem mais ordena, Jorge Calado

A série intitulada «...uma questão de Química» é constituída por um conjunto de motivadoras conferências, proferidas por notáveis e conhecidas figuras da investigação em química no nosso país e sobre temas essenciais da ciência contemporânea. As reflexões, bem como os debates com o público, vão servir certamente para solidificar e perfumar os caminhos que teremos de percorrer neste século à procura de um mundo melhor. Jorge Calado foi o primeiro conferencista deste ciclo, no dia 19 de Outubro, na Fundação Calouste Gulbenkian, com "A Química é quem mais ordena":

"A química quer saber de que é que são feitas as coisas, e o que acontece quando pomos as coisas em contacto umas com as outras (para fazer ainda outras). Ordenar é contar.

Desde o início a química contou com números pequenos. Os Gregos reduziram tudo a quatro elementos e a quatro propriedades, mais os amores e ódios entre eles. Como diziam os pitagóricos, "Avancem do um até ao quatro e surge o dez, a mãe primordial de todas as coisas". De facto, $1+2+3+4=10$, tantos quantos os dedos das duas mãos. A química moderna começa com a redefinição do conceito de elemento e a sua associação ao átomo. No final do século XVIII e princípio do século XIX percebeu-se que os elementos se combinavam na proporção de números inteiros e pequenos. Por exemplo, a ferrugem (óxido férrico) são três partes de oxigénio e duas de ferro. Daí à teoria atómica (de Dalton) foi um passo. Entretanto percebia-se que a química da vida (plantas e animais) estava ligada ao carbono (e ao hidrogénio, oxigénio, nitrogénio, etc). A química inorgânica era mais difícil de sistematizar. Até que surgiu uma espécie de kalmuque russo, com grandes qualidades pedagógicas e a precisar de ganhar dinheiro. Escreveu um livro - o melhor livro de química de todos os tempos? - e houve luz, com a Tabela Periódica. Dalton e Mendeleev puseram a química na ordem, e hoje é a química quem mais ordena. Pelo meio, houve várias revoluções..."
Serões da Bonjóia :: "Haja Luz!: Viagem à Volta de um Livro", Jorge Calado

Os Serões da Bonjóia pretendem ser o reviver de tertúlias à moda portuense e consistem em conferências/encontros/concertos/debates, regulares, subordinados a temas e actividades diversas, na Quinta da Bonjóia. O objectivo é contribuir para a formação/ informação dos cidadãos em geral e promover a dinamização de uma zona menos conhecida da Cidade. E porque 2011 é o Ano Internacional da Química, no dia 20 de Outubro, o convidado foi o Prof. Doutor Jorge Calado com "Haja Luz!: Viagem à Volta de um Livro":

"O livro como objecto. Antecedentes e inspirações. Porque é que está tudo ligado. A importância do fogo. De que é que são feitas as coisas? O caos e o gás. A importância da electricidade. A serendipidade e a descoberta simultânea. Os números inteiros e pequenos. A teoria atómica. O prazer da descoberta. A ordem mental das coisas. Visualização e imaginação. $E$ agora?"

Um Serão da Bonjóia, onde o autor misturou a sua experiência pessoal com a química em geral, tentando mostrar porque é que a química é a ciência central.

\section{Ciclo de Conferências Científicas} :: "Os Meus Heróis: viagens à volta da Química", Jorge Calado

O Centro de formação de Associação de Escolas de Vila Nova de Famalicão tem vindo, desde o ano transacto, a desenvolver ciclos de conferências científicas. Este ano lectivo, dado estarmos em 2011, Ano Internacional da Química e Ano Internacional da Floresta, iniciou-se um II Ciclo com 3 temas de Química e um sobre a Floresta Portuguesa. A primeira conferência, Os Meus Heróis: viagens à volta da Química, pelo Prof. Doutor

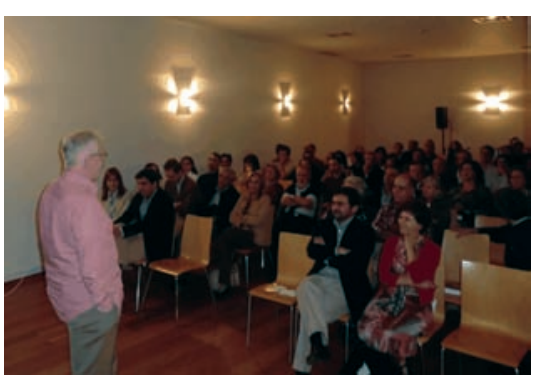

Prof. Doutor Jorge Calado no Serão da Bonjóia
Jorge Calado, foi no dia 21 de Outubro. Neste dia teve também lugar a apresentação do livro do conferencista, Haja luz! Uma história da Química através de tudo.

From molecules to the course of infection, Maria Mota, Instituto de Medicina Molecular - Lisboa

Dia 26 de Outubro na Biblioteca da Faculdade de Ciências e Tecnologia da Universidade Nova de Lisboa

\section{Química e a Investigação Forense,} Maria João Caldeira, Laboratório de Polícia Científica - Polícia Judiciária Dia 26 de Outubro no Anfiteatro 4, CLAV, Universidade de Évora

\section{Expressão Plástica e Artística:}

\section{Teatro Quimicómico}

No âmbito das celebrações do Ano Internacional da Química, a Universidade de Aveiro recebeu o teatro de ciência «Quimicómico», que tem na Química o elemento central de toda a peça. Este espectáculo, destinado a crianças a partir dos quatro anos, esteve em cena no auditório da Reitoria da Universidade de Aveiro no dia 28 de Outubro, com uma sessão dedicada exclusivamente às escolas e, no dia 29 de Outubro, para o público geral.

«Quimicómico» é um espectáculo de teatro cómico, em que a Química é o elemento central de toda a peça. Tratase de um espectáculo dinâmico, com um discurso muito acessível e efeitos visuais surpreendentes, que promete divertir o público e, ao mesmo tempo, despertar a veia científica de miúdos e graúdos. Mensagens invisíveis, um relógio vegetal, uma máquina de aumentar/encolher coisas, um chuveiro de $\mathrm{CO}_{2}$, líquidos que mudam de cor, pipocas e bombocas, couve roxa, cores fluorescentes e fosforescentes, alguma sátira social, muita música (toda original) e acima de tudo muito e bom

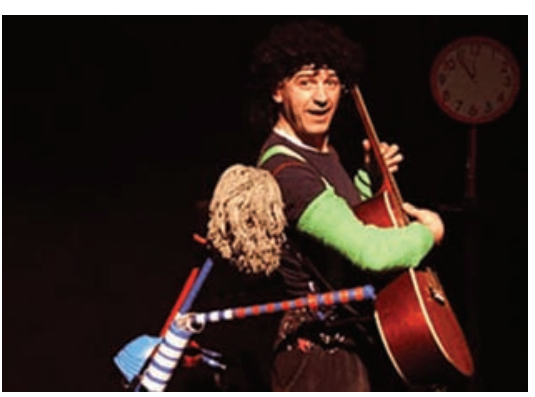

Ensaio do Teatro Quimicómico 
humor, eis os ingredientes para um espectáculo que não deixará ninguém indiferente.

Este espectáculo resultou de uma produção da companhia de teatro «Encerrado para Obras» em co-produção com o Exploratório Infante D. Henrique - Centro Ciência Viva de Coimbra.

\section{ConferêncIAs / PALESTRAS:}

\section{"A Propósito da Falácia"}

Nos dias 26 e 27 de Outubro, a Faculdade de Ciências da Universidade do Porto, com o ciclo de debates "A propósito da Falácia", despertou a comunidade académica com a discussão de temas como ética e ciência. O primeiro dia contou com a apresentação do livro "Falácia" do cientista Carl Djerassi e o debate "Ciência e Ética", com a presença de Alexandre Quintanilha. Já no segundo dia discutiu-se a "Arte e Ciência - diferentes perspectivas" e contou com a presença de Carl Djerassi, Lúcia Rosas (FLUP) e Maria Clara Paulino (FLUP). A moderar os debates estiveram Zulmira Santos e Manuel João Monte.

\section{EXPOSIÇÕES E OUtRos EvEntos:}

Doutoramento Honoris Causa Carl Djerassi

Carl Djerassi, Prof. Emérito de Química da Universidade de Stanford, recebeu o seu $25^{\circ}$ título de Doutor Honoris Causa, concedido pela Universidade do Porto, sob proposta da Faculdade de Ciências, no dia 28 de Outubro, no Salão Nobre da Reitoria da Universidade do Porto.

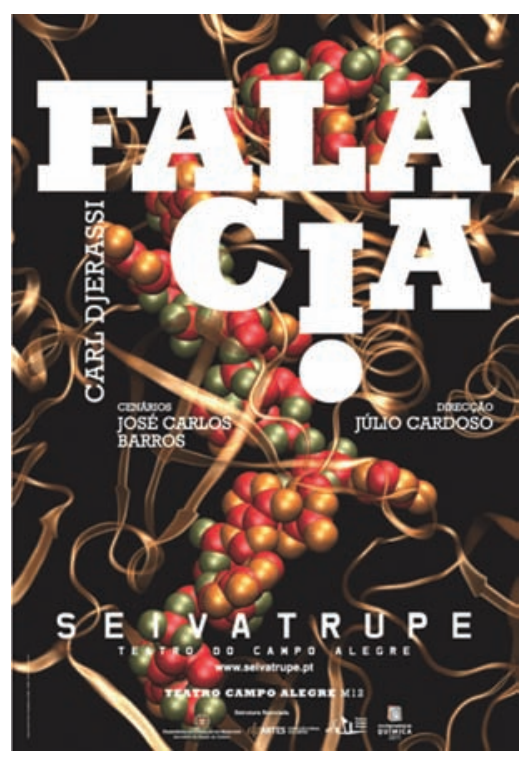

Expressão Plástica e Artística:

\section{Teatro Falácia}

Falácia não é um espectáculo qualquer mas, na realidade será um espectáculo INVULGAR!...

Invulgar porque não é uma coisa que se veja todos os dias. Invulgar porque talvez nunca mais volte a ter a possibilidade de ver. E mais: FALÁCIA é feita a pensar em si!

Nesta peça há um debate vivo, audacioso e cativante, com sentimentos amorosos a cruzarem-se e a prender o espectador pelo "bico". Num importante museu europeu, em Viena de Áustria, encontra-se a estátua de um rapaz nu, atribuída à era romana e que é a jóia da coroa do museu. Mas a ciência, através da química, desmistifica aquela era. E o valor artístico da obra, para além da data da sua feitura? Aqui está um espectáculo para quem se interessa por tudo que é importante na vida mas, muito especialmente, para quem se interessa por QUÍMICA e/OU MUSEOLOGIA.

Dia 28 de Outubro foi a estreia do espectáculo Falácia, do grande cientista de renome mundial e dramaturgo Carl Djerassi. Entre 29 de Outubro e 30 de Novembro esteve em cena todos os
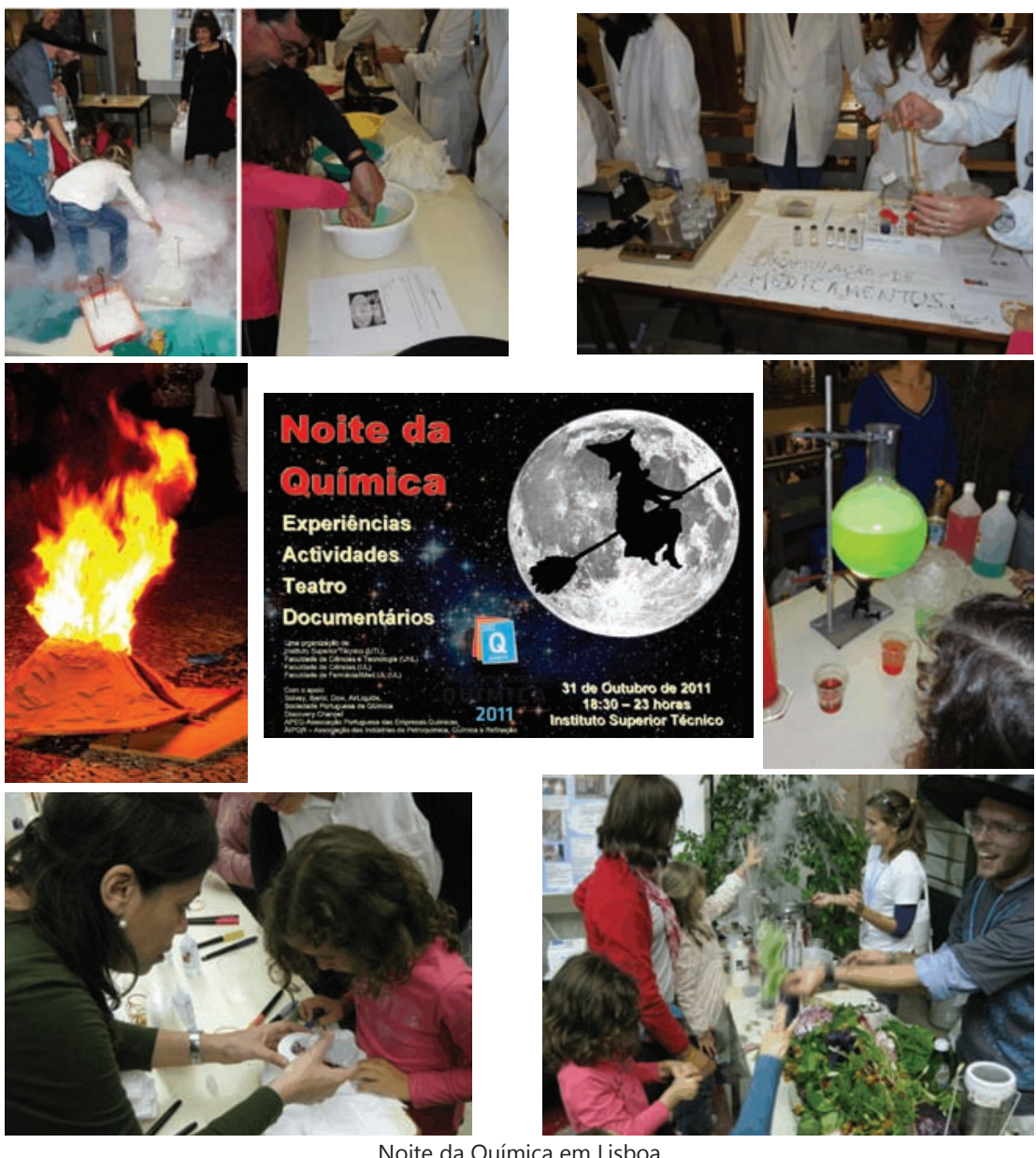

dias, excepto nas segundas-feiras, no Teatro do Campo Alegre, Porto. Este espectáculo inseriu-se no Centenário da Universidade do Porto e nas comemorações do Ano Internacional da Química.

\section{EXPOSIÇÕES E OUtROS Eventos:}

\section{Noite da Química :: Lisboa}

O Instituto Superior Técnico (Universidade Técnica de Lisboa), as Faculdades de Ciências e de Farmácia (Universidade de Lisboa) e a Faculdade de Ciências e Tecnologia (Universidade Nova de Lisboa) apresentaram "A Noite da Química" no dia 31 de Outubro a partir das 18h30. Experiências, Actividades, Documentários e uma peça de Teatro sobre Marie Curie (pela Companhia Teatro Extremo) compuseram esta noite especial, integrada nas comemorações do Ano Internacional da Química.

LIVRos E PublicaçõEs:

Newsletters mensal SPQ e quinzenal AIQ

Vanda Capitolino (quimica2011@spq.pt) www.spq.pt/quimica2011
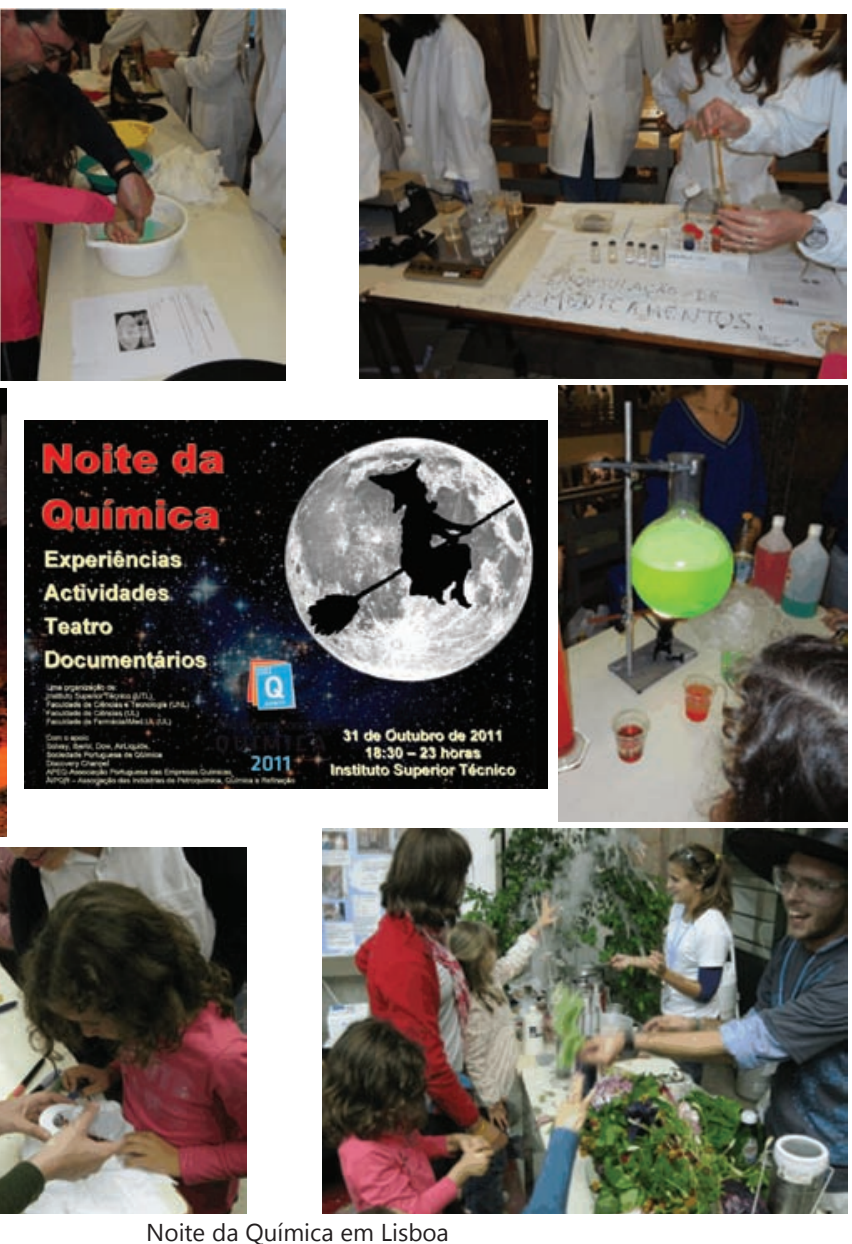